\title{
EFFEGTS OF $3^{\prime}, 5^{\prime}$-GYGLIC ADENOSINE MONOPHOS- PHATE AND ITS DIBUTYRYL DERIVATIVE ON THE MOTILITY OF ISOLATED RAT ILEUM
}

\author{
AKIYOSHI KAWASAKI, TAKESHI KASHIMOTO \\ AND HIROSHI YOSHIDA \\ Department of Pharmacology, Faculty of Medicine, Osaka University, Kila-ku, Osaka \\ Received for publication March 20, 1969
}

To clarify the mechanisms regulating the function of smooth muscle the relations of changes in metabolism to its function have been examined by several investigators. Adrenaline is known to depress the motility of the intestine and the uterus and it also increases the content of cyclic AMP and the activity of phosphorylase a (1-3). Experiments have shown that on addition of adrenaline the increasc in phosphorylase a activity is preceded by the increase in the cyclic AMP level and the decrease in motility $(1,2)$. Thus, the relation between the content of cyclic AMP and the motility of the intestine seems interesting. This paper reports the effects of cyclic AMP and its derivative on isolated ileum. The hypothesis that cyclic AMP is an intracellular messenger for transmitting information from outside the cell by hormones and neurotransmitters, including catecholamines $(4,5)$ is discussed on the basis of the results.

\section{METHODS}

Healthy adult rats were killed by a blow on the head. The ileum was removed and a length of about $2 \mathrm{~cm}$ was cut out and incubated in an organ bath (Magnus's bath) containing $5 \mathrm{ml}$ of Tyrode solution with continuous aeration at $35 \mathrm{C}$ by the standard technique. The high $\mathrm{K}^{+}$medium used containcd $131.5 \mathrm{~mm}$ of $\mathrm{KCl}, 0.36 \mathrm{~mm}$ of $\mathrm{CaCl}_{2}, 0.35$ $\mathrm{mm}$ of $\mathrm{KH}_{2} \mathrm{PO}_{4}, 10 \mathrm{~mm}$ of $\mathrm{KHCO}_{3}$ and $5 \mathrm{~mm}$ of glucose. Movement of the ileum was recorded isotonically on a smoked drum with a kymograph or with a polygraph using a SB-IT type transducer (Nihon Kohden Co.).

Cyclic AMP and dibutyryl-cyclic AMP were kindly given by Takeda Chemical Industries.

\section{RESULTS}

1. Effects of various nucleotides and caffeine on the motility of the ileum in Tyrode solution As shown in Fig. 1, addition of cyclic AMP or AMP caused a transient relaxation

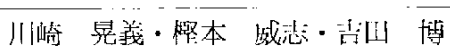

The abbreviations used are;

cyclic AMP : 3'5'-cyclic adenosine monophosphate

DCI : dichloroisoproterenol
} 


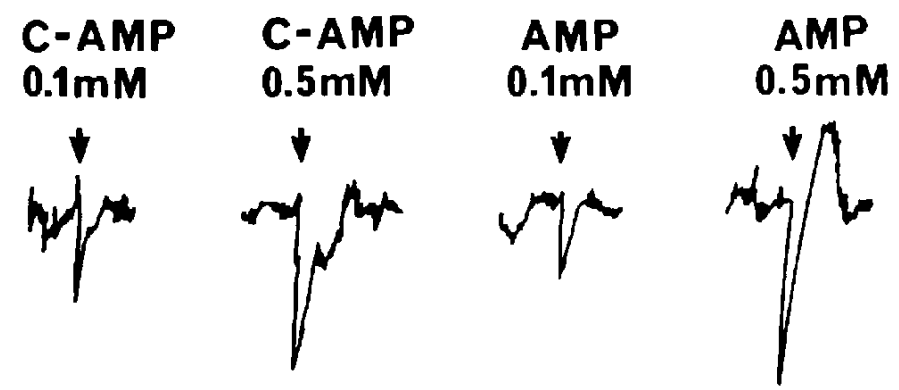

FIG. 1. Effects of cyclic AMP and AMP on isolated rat ileum in Tyrode solution.

\section{DBC-AMP}
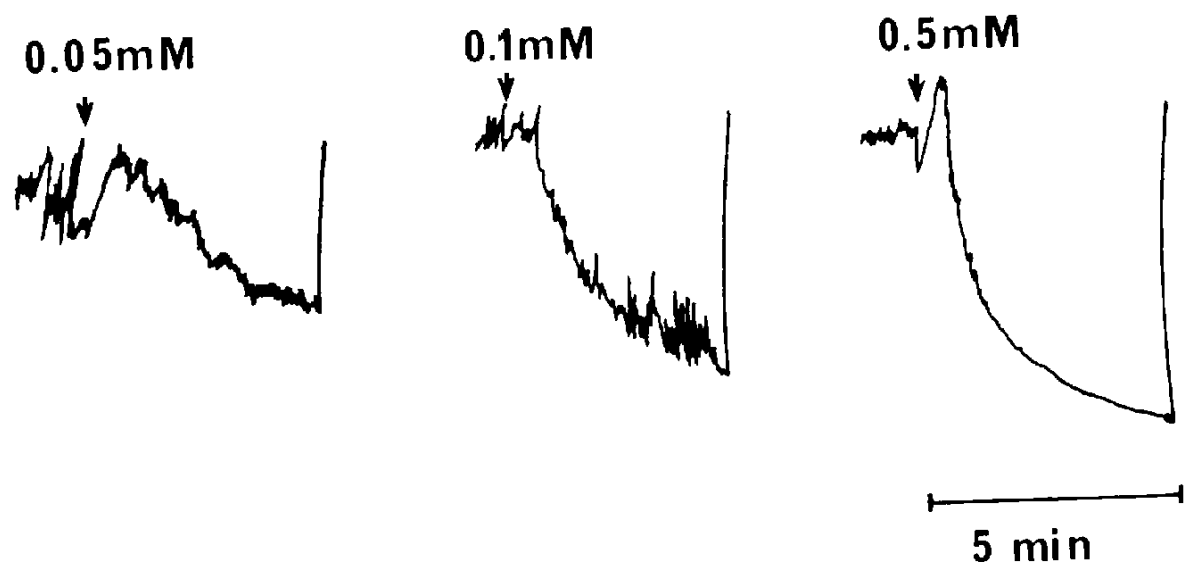

FIG. 2, Effect of dibutyryl-cyclic AMP on isolated rat ileum in Tyrode solution.

\section{Caffeine}

$0.2 \mathrm{mM}$

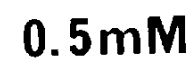

$1.0 \mathrm{mM}$
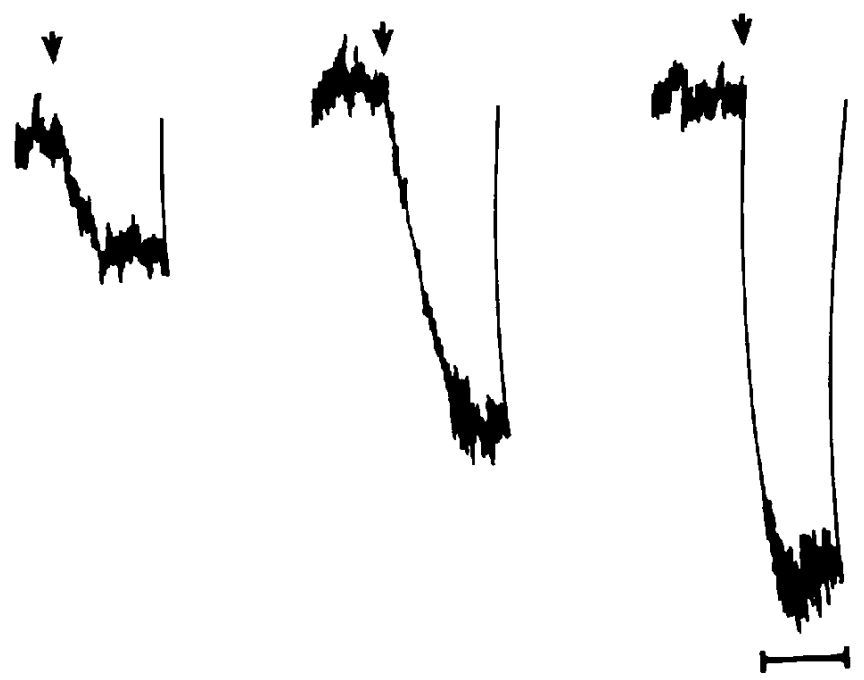

$3 \mathrm{~min}$

Fig. 3. Fffect of caffeine on isolated ileum in Tyrode solution. 
which in some cases was followed by contraction. There was no significant difference between the effects of these two drugs. ATP and ADP caused prolonged contraction of the ileum under our conditions.

Addition of dibutyryl-cyclic AMP caused relaxation after a latent period of 30-90 seconds, as shown in Fig. 2. The relaxation seemed to depend on the concentration of dibutyryl cyclic AMP: on increasing the dose, the response was strengthened and the latent period was shortened. The effect of dibutyryl-cyclic AMP did not disappear immediately after washing away the drug and 30-60 minutes was required for complete return to the level before treatment.

Caffeine also caused relaxation, the extent of which depended on the concentration of caffeine, as shown in Fig. 3. In the presence of caffeine the effect of cyclic AMP on the ileum was unchanged but the relaxing effect of dibutyryl-cyclic AMP was strengthened in 2 of 10 experiments.

2. Effects of nucleotides and caffeine on the ileum in high $\mathrm{K}^{+}$medium

As shown above, dibutyryl-cyclic AMP, like adrenaline, caused relaxation, but cyclic AMP had a quite different effect. Cyclic AMP is considered to be non-diffusible, or at

\section{Caffeine}

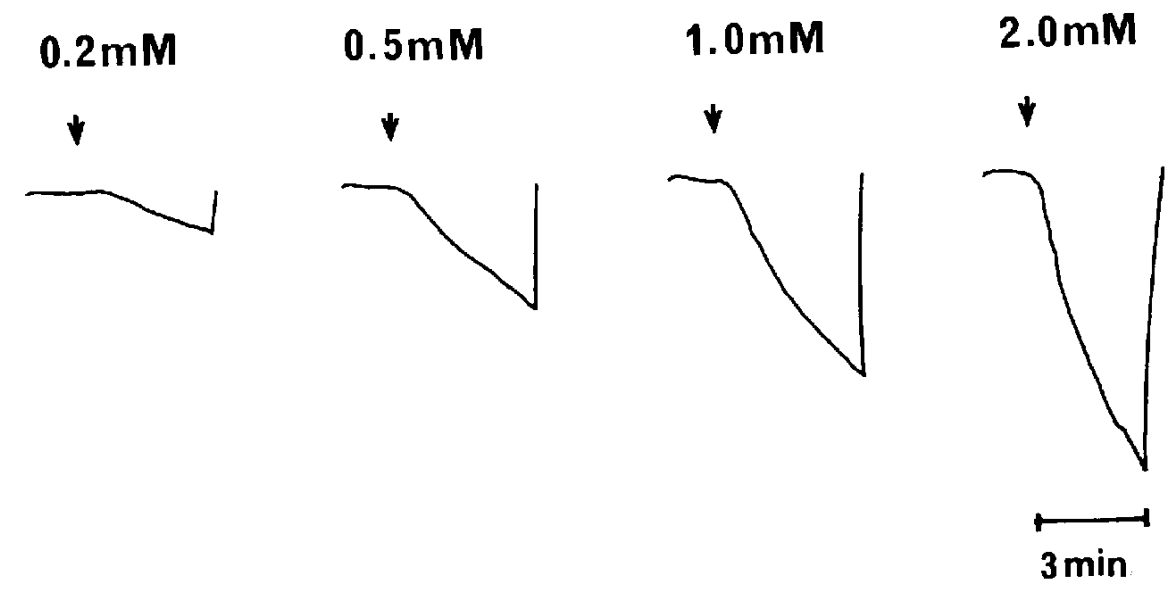

Fig. 4. Effect of caffeine on isolated rat ileum in high $\mathrm{K}^{+}$solution.

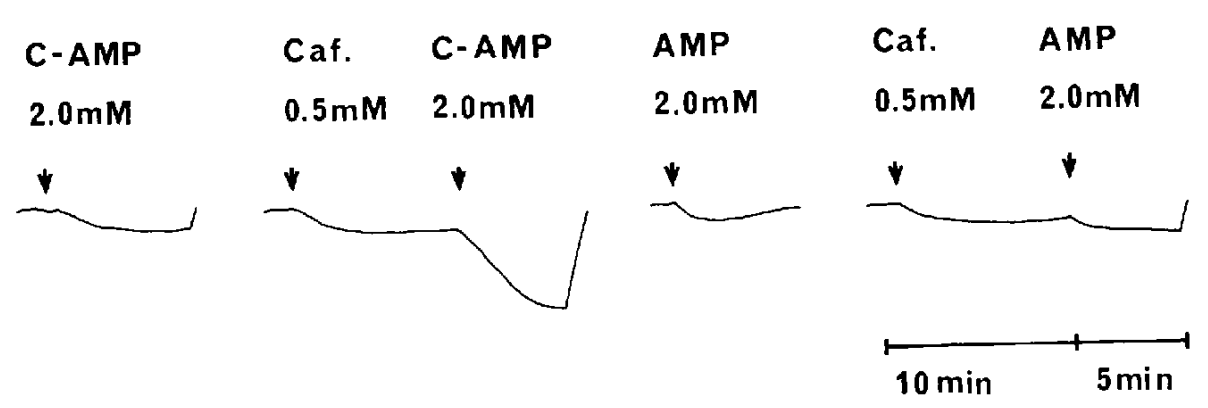

FIG. 5. Influence of caffeine on the responses of isolated rat ileum to cyclic AMP and AMP in high $\mathrm{K}^{+}$medium. 
least not to penetrate the cell mèmbrane appreciably. Accordingly following experiments were carried out in high $\mathrm{K}^{+}$medium, in which the muscle membrane is in a depolarized state and becomes more permeable.

In the absence of caffeine, $0.5-5.0 \mathrm{~mm}$ of cyclic AMP or AMP had no effect or only a slight relaxing effect.

However, in presence of caffeine $(0 . \overline{5}-1.0 \mathrm{~mm})$, the difference in the effects of cyclic AMP and AMP was clearly demonstrated. Caffeine itself at concentrations of 0.2 to $2 \mathrm{~mm}$ caused relaxation, as shown in Fig. 4., and after pretreatment with $0.5 \mathrm{~mm}$ caffeine for 10 minutes addition of $2 \mathrm{~mm}$ cyclic AMP caused remarkable relaxation (Fig. 5) but the effect of 2 mM AMP was not significantly changed by the presence of caffeine. The results are shown as a dose-response curve in Fig. 6.
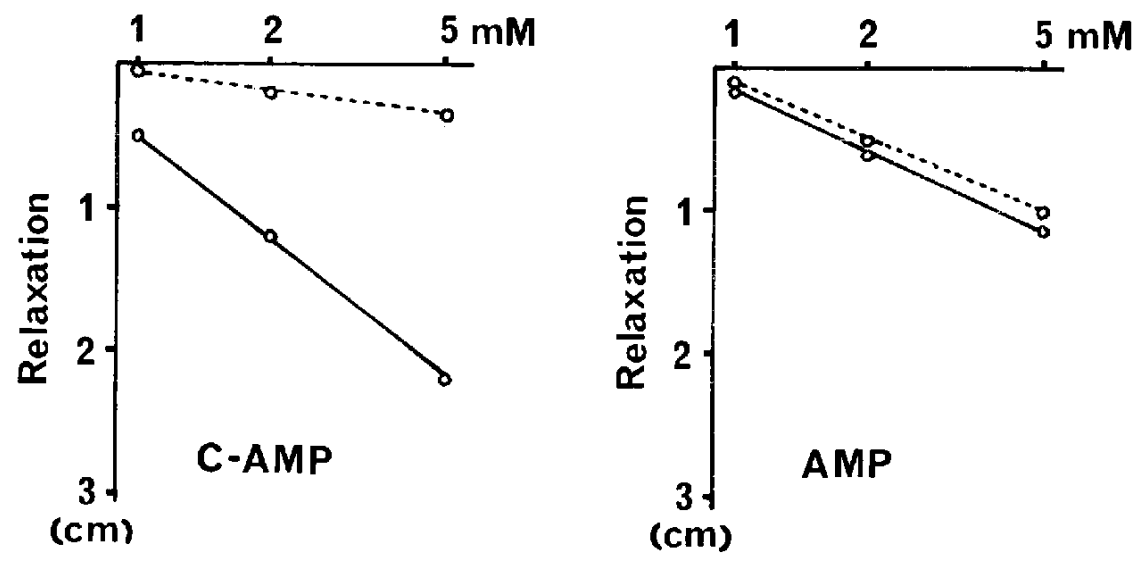

\section{without Caffeine with Caffeine $(0.5 \mathrm{mM})$}

FIG. 6. Dose-response curves of cyclic AMP and AMP in the presence and absence of caffeine on isolated rat ileum in high $\mathrm{K}^{+}$medium.

\section{DBC-AMP}
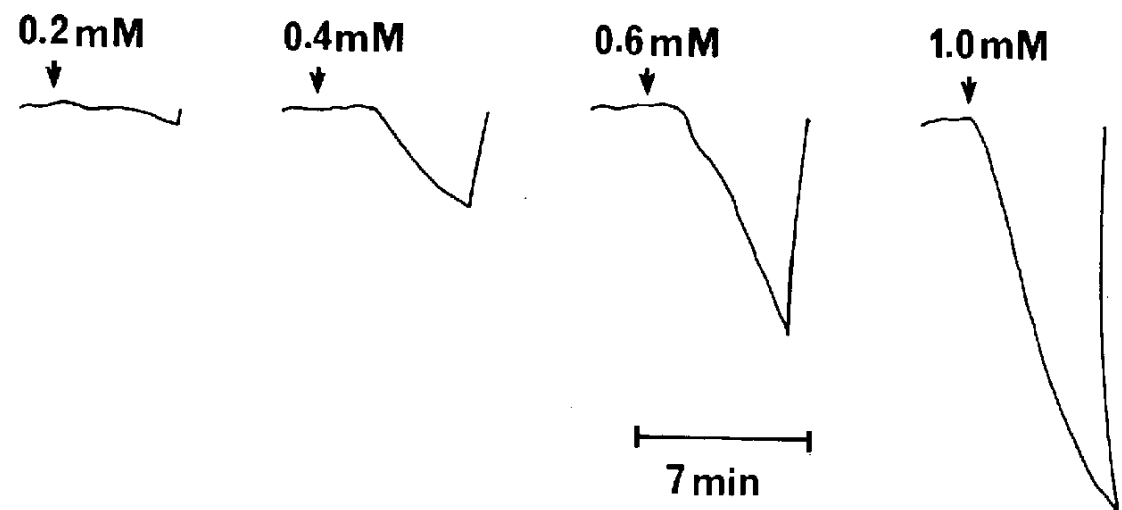

FiG. 7. Effect of dibutyryl-cyclic AMP on isolated rat ileum in high $\mathrm{K}^{+}$medium. 

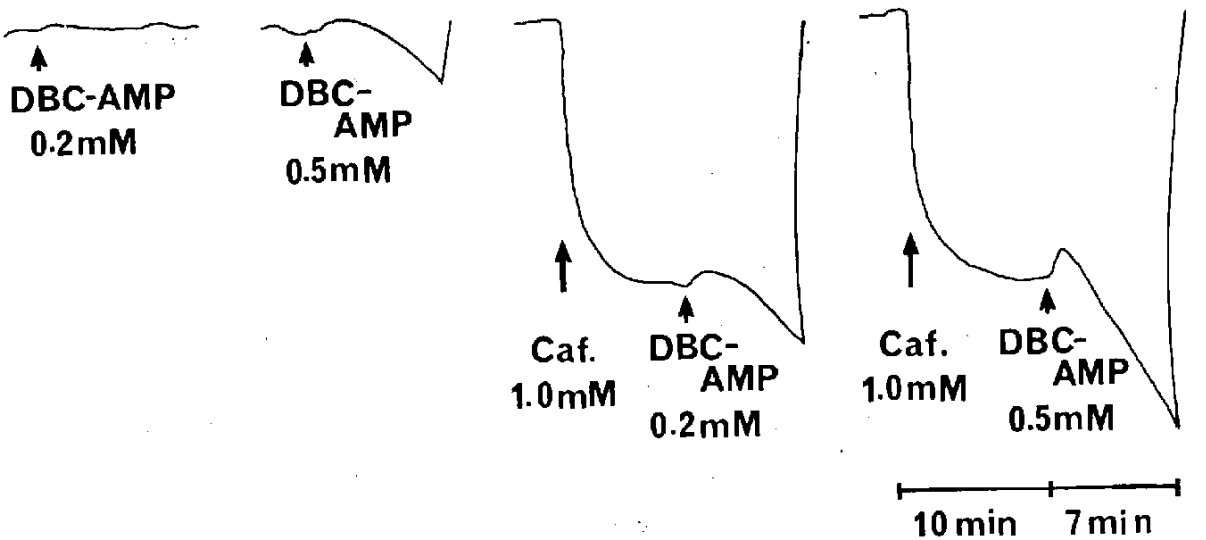

FIG. 8. Influence of caffeine on the response of isolated rat ileum in high $\mathrm{K}^{+}$medium to dibutyryl-cyclic AMP.

Dibutyryl-cyclic AMP (0.2-1.0 mu) caused relaxation of isolated ileum in high $\mathrm{K}^{+}$ solution after 30 to 90 second latent period (Fig. 7) and the effect did not disappcar after washing it away, as with normal Tyrode solution. The relaxing effect of dibutyrylcyclic AMP was potentiated by caffeine, as shown in Fig. 8, and the optimal concentration of caffeine for potentiation seemed to be $0.5-1.0 \mathrm{~mm}$.

3. Influence of dichloroisoproterenol on the relaxing effect of dibutyryl-cyclic $A M P$

1) Experiments in Tyrode solution

Addition of DCI ( $0.1 \mathrm{~mm})$ caused a transient relaxation of the ileum with subsequent return to the initial level. The relaxing effect of isoproterenol $\left(2 \times 10^{-n} \mathrm{M}\right)$ was completely abolished by addition of DCI 8 minutes previously, but the effect of dibutyryl-ayclic AMP

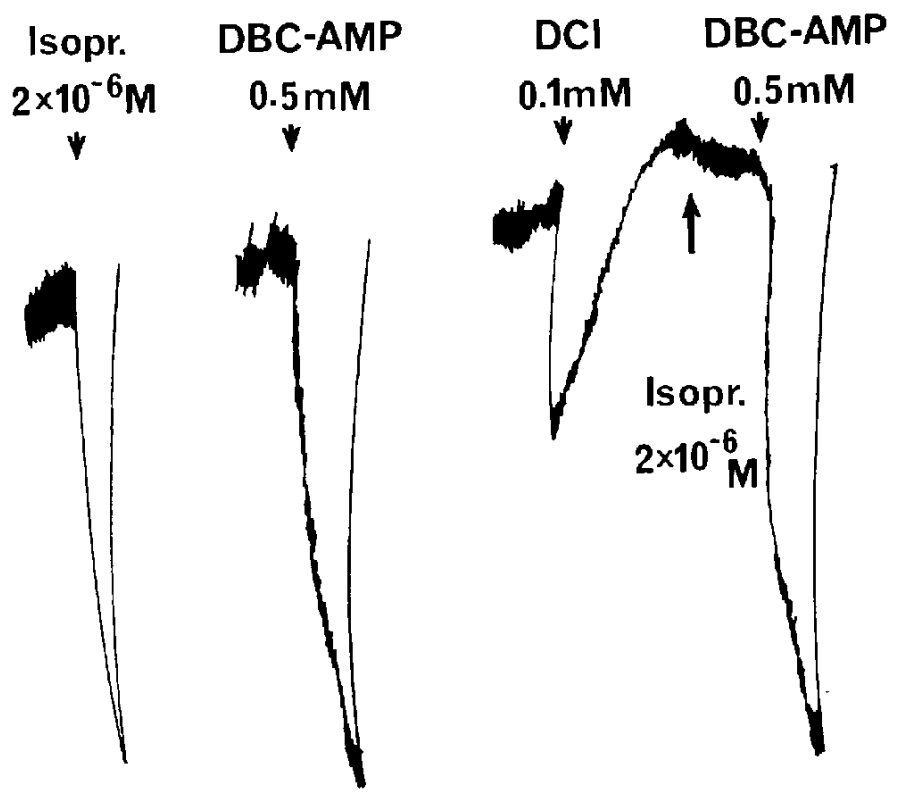

FIG. 9. Effects of isoproterenol and dibutyryl-cyclic AMP in the presence of DCI on isolated rat ileum in Tyrode solution. 
$(0.5 \mathrm{~mm})$, which caused a similar degree of relaxation as isoproterenol $\left(2 \times 10^{-6} \mathbf{M}\right)$, was not influenced by DCI (Fig. 9).

2) Experiments in high $\mathrm{K}^{+}$medium

In high $\mathrm{K}^{+}$medium $0.01-0.1 \mathrm{~mm}$ of DCI caused a strong persisting relaxation of the ileum, so experiments were carried in the presence of $1.0-2.0 \mathrm{mM} \mathrm{Ca}^{++}$to maintain a certain level of muscle tone. As shown in Fig. 10, DIC did not affect the relaxing effect of dibutyryl-cyclic AMP but reduced the effect of isoproterenol to $20 \%$ of the control value.

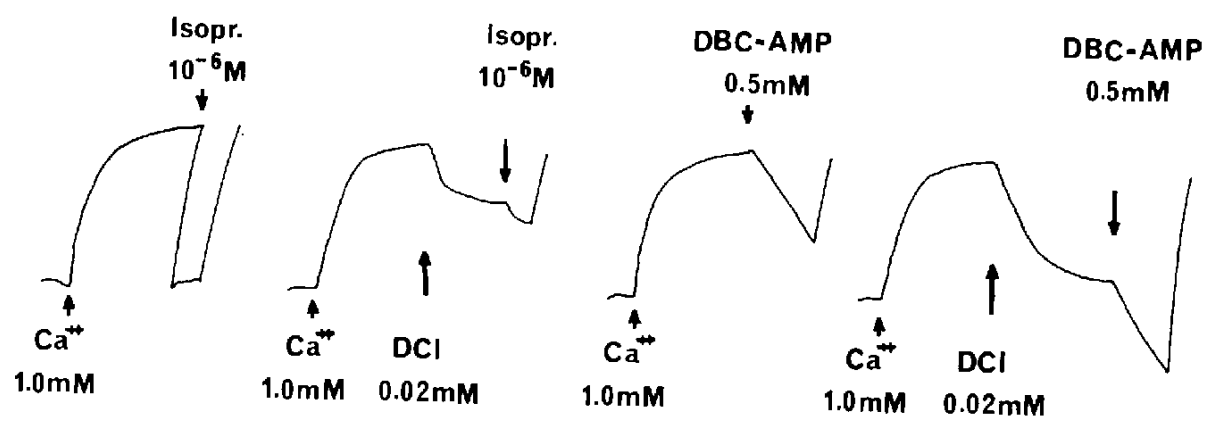

FIG. 10. Effects of isoproterenol and dibutyryl-cyclic AMP in the presence of DGI on isolated rat ileum in high $\mathrm{K}^{+}$medium.

\section{DISCUSSION}

The effects of various kinds of nucleotides on the motility of isolated ileum have been investigated $(6,7)$. But as far as we know, no specificity of action of cyclic AMP has been demonstrated. This is also true in our experiments with rat ileum in Tyrode solution without caffeine. However, in high $\mathrm{K}^{+}$medium with caffeine cyclic $A M P$ showed a remarkable relaxing effect on the ileum though the effect of AMP, itself was slight. A derivative of cyclic AMP, dibutyryl-cyclic AMP, caused marked and prolonged relaxation after a 30-90 second latent period even in Tyrode solution without caffeine. The difference between the effects of cyclic AMP and dibutyryl-cyclic AMP can be explained as follows (8). Cyclic AMP is probably not permeable, or at least penetratcs the cell membrane less well than dibutyryl-cyclic AMP. Moreover, cyclic AMP is more easily hydrolyzed by phosphodiestcrase, which is inhibited by caffeine, than dibutyryl-cyclic AMP. Then, it seems likely that cyclic AMP specifically causes relaxation of the ileum among nucleotides. Our findings on the ileum are in good agreement with those of Dubbs and Robison (9) on the uterus. On the other hand, it has been reported that cyclic AMP increases the heart rate, cardiac output $(10,11)$ and response of an aortic strip to noradrenaline (12) and also causcs liberation of glucose from liver $(8,13)$. These effects of cyclic AMP are similar with those of catecholamine on various tissues. These findings support the possibility that cyclic AMP acts as intracellular messenger regulated by catecholamine, as postulated by Sutherland and co-workers $(4,5)$. However, there is an apparent discrepancy between the concentration of cyclic AMP we used and its intracellular concentration in the ileum even in the presence of catecholamine (3). This apparent 
discrepancy may also be explained by considering the low penetration of cyclic AMP into the cell and its rapid hydrolysis by phosphodiesterase inside the cell (8). Accordingly, it seems probable that catecholamine causes relaxation of the ileum by increasing the cyclic AMP level inside the cell by activation of adenylcyclase. This means that adenylcyclase may be a receptor of catecholamine. However it is considered that there are two types of catecholamine receptor, $\alpha$ and $\beta$, both related to inhibitory response of the intestine. Activation of the $\beta$-receptor was reported to be related with depression of contraction caused by $\mathrm{Ca}$, and the $\alpha$-receptor has been suggested to act at the surface membrane $(14,15)$. At present, it seems likely that adenyl cyclase is the $\beta$-receptor of catecholamine in the intestine. This possibility is supported by our results showing that relaration of the ileum caused by dibutyryl-cyclic AMP was not blocked by dichloroisoproterenol, a typical adrenergic $\beta$-blocker, and similar results on the uterus by Dobbs and Robison (9). It seems probable that cyclic AMP regulates the contraction-relaxation cycle of the smooth muscle beyond the process in which adrenergic $\beta$-receptor participates, but the mechanism of relaxation of the ileum by cyclic AMP is still uncertain.

\section{SUMMARY}

1. Dibutyryl-cyclic AMP and caffeine caused relaxation of the rat ileum in Tyrode solution, but ATP and ADP caused contraction, and cyclic AMP and AMP caused transient relaxation followed by contraction.

2. The relaxing effect of dibutyryl-cyclic AMP on the ileum in high $\mathrm{K}^{+}$medium was potentiated by caffeine. In high $\mathrm{K}^{+}$medium, cyclic AMP like AMP, had no significant relaxing effect on the ileum. But, by the presence of caffeine in high $\mathrm{K}^{+}$medium, cyclic AMP caused marked relaxation while AMP had little effect.

3. The relaxing effect of dibutyryl-cyclic AMP on isolated rat ileum was not blocked by DCI, either in normal Tyrode solution or in high $\mathrm{K}+$ medium.

4. The possibility that adenyl cyclase is a $\beta$-receptor of catecholamine and that cyclic AMP, formed by the enzyme, may act as an intracellular regulator in smooth muscle causing relaxation of the ileum, is discussed on the basis of the results.

\section{REFERENCES}

1) Diamond, J. and Brody, T.M.: J. Pharmac. exp. Ther. 152, 202 (1966)

2) Diamond, J. And Brody, T.M.: J. Pharmac. exp. Ther. 152, 212 (1966)

3) Bueding, E., Butcher, R.W., Hawrins, J., Timms, A.R. and Sutherland, E.W.: Biochim. biophys. Acta 115, $173(1966)$

4) Sutherland, E.W. And Robison, G.A.: Pharmac. Rev. 18, 145 (1966)

5) Robison, G.A., Butcher, R.W. and Sutherland, E.W.: Ann. N.Y. Acad. Sci. 139, 733 (1937)

6) Kim, T.S., Shulman, J. and Levine, R.A.: J. Pharmac. exp. Ther. 163, 36 (1958)

7) Mihichi, E., Clarke, D.A. and Philips, F.S.: J. Pharmac. exp. Ther. 111, 335 (1954)

8) Posternak, T. and Sutherland, E.W.: Biochim. biophys. Acta 65, 558 (1932)

9) Dobes, J.W. and Rogison, G.A.: Fedn Proc. 27, 352 (1958)

10) Levine, R.A. And Vogel, J.A.: J. Pharmac. exp. Ther. 151, 262 (1966) 
11) Levien, R.A., Dixon, L.M. and Franklin, R.B.: Clin. Pharmac. Ther. 9, 168 (1967)

12) Bartelstone, H.J., Nasmyth, P.A. and Telford, J.M.: J. Physiol. 188, 159 (1967)

13) Northrop, G. and Parks, R.E. JR.: J. Pharmac. exp. Ther. 145, 87, 135 (1964)

14) Jenkinson, D.H. and Morton, I.K.M. : Ann. N.Y. Acad. Sci. 139, 762 (1967)

15) Brody, T.M. and Dlamond, J.: Ann. N. Y. Acad. Sci. 139, 772 (1967) 